\title{
Chapter 20 \\ How to Talk About Academic Integrity so Students Will Listen: Addressing Ethical Decision-Making Using Scenarios
}

\author{
Lee-Ann Penaluna $(\mathbb{D}$ and Roxanne Ross $(\mathbb{D}$
}

\begin{abstract}
The field of academic integrity in higher education has made significant gains in exploring the proliferation of integrity issues, the frequency of student misconduct behaviours, and in identifying strategies for embedding academic integrity education more broadly into the curriculum. Regardless of calls for institution-wide approaches which focus on preventing academic misconduct, those of us engaged in the field can attest that there will always be a need to address academic misconduct behaviours and support the development of those students who engage in them. As student affairs practitioners in a Canadian post-secondary institution, we present our approach to creating meaningful teaching and learning experiences that enable students with misconduct violations to critically explore potential misconduct situations and practice the skills needed to make alternative decisions. Utilising existing work that frames academic integrity as 'standards of practice', this chapter demonstrates our application of key themes from the academic integrity literature within our teaching and learning practice. Recognizing that mandated academic integrity education can be a challenging learning experience, we discuss our approach to engaging these students in analyzing the common situational factors that postsecondary students face that pose potential academic integrity conflicts and the way ethical decision-making frameworks can support their ability to navigate academic integrity concerns in the future. We conclude the chapter with our key learnings and recommendations for implementing an engaging experience with students who are mandated to attend instruction following an academic integrity violation.
\end{abstract}

Keywords Academic integrity $\cdot$ Canada $\cdot$ Decision making $\cdot$ Student affairs • Student misconduct

\footnotetext{
L.-A. Penaluna $(\bowtie) \cdot R$. Ross

University of Calgary, Calgary, Canada

e-mail: leeann.penaluna@ucalgary.ca

R. Ross

e-mail: rossr@ucalgary.ca
}

S. E. Eaton and J. Christensen Hughes (eds.), Academic Integrity in Canada,

Ethics and Integrity in Educational Contexts 1 ,

https://doi.org/10.1007/978-3-030-83255-1_20 
The predominant post-secondary institutional framing of academic integrity in ethical-legal terms has been widely critiqued as problematic (Adam et al., 2017; Bertram Gallant, 2008) with studies involving students illustrating the potential ways that this positioning can alienate students and ultimately hinder their learning (Ashworth et al., 1997; Gullifer \& Tyson, 2010). Scholars argue that presenting academic misconduct as a student's moral failing or refusal to comply to rules situates the problem solely with the student (Bertram Gallant, 2008) and oversimplifies the nuances within academic integrity constructs such as plagiarism and collusion, for which studies have demonstrated that even faculty are challenged to arrive at unified definitions (Barrett \& Cox, 2005). This has led for calls to move away from the punitive approaches that ensue from ethical-legal institutional discourses to a situating of academic integrity as a teaching and learning issue within the academy (Bertram Gallant, 2008; East \& Donnelly, 2012). A teaching and learning focus allows for an understanding of students as learners, grappling with news ways of knowing and presenting knowledge, and thereby presents greater opportunities to engage students in discussions of academic integrity in all its complexities. In the context in which we teach academic integrity, mandated sessions for students who have experienced issues with our academic misconduct policy, a teaching and learning approach is essential. While there has been an increasing focus on teaching and learning approaches to academic integrity in the literature (East \& Donnelly, 2012; Orr, 2018), very little discussion of theory and practice exists in relation to supporting the learning and development of students who have had academic misconduct breaches. In particular, there is a dearth of literature sharing practical approaches that address the challenges and sensitivities involved in engaging students who have experienced academic misconduct. This chapter focuses on our approach to delivering academic integrity education to those who have recently been found responsible for an academic misconduct and, have been mandated to attend an academic integrity workshop. In both shifting and deepening the conversation from the punitive to the developmental, we hope to contribute to the scarcity of literature that explores the methods by which those students that have been found responsible for an academic misconduct violation can be supported through educational programming to avoid recidivism. Taking direction from and offering critique of the existing literature, we present and critically assess our instructional approach. In sharing our experience, we aim to expand upon the scarcity of literature that informs practice with this population of students and seek to emphasize the necessity of a nuanced perspective of academic integrity, one that incorporates educational responses to, as East (2010) suggests, issues of "convention" (p. 69) and ethical dilemmas.

\section{Context}

As student affairs practitioners in academic support services, our work is situated within a student-facing unit in a large post-secondary institution in Western Canada. Our department provides a range of services broadly classified into three areas: 
advising, learning, and writing. Academic integrity programming is situated within the learning classification. In addition to web-based educational resources including hyperlinks to the Student Academic Misconduct Policy and Procedure, the Student Academic Integrity Handbook, factsheets and other online resources, two core workshops are offered: Academic Integrity: Strategies to Avoid Plagiarism and Academic Integrity: Collaborating with Peers. Both workshops were developed in 2016 as a collaborative endeavour with faculties and Library staff for the primary purpose of providing academic integrity education for those students who had academic integrity breaches, and who had previously been required to attend individual meetings with a member of our unit's staff. In addition to addresses issues in scalability, we transitioned our one-on-one approach to academic integrity instruction to group sessions, in an effort to foster provide students with a more engaging and collaborative learning experience. Although the academic integrity workshops are open to all students, attendees are almost exclusively students who have been found responsible for academic integrity violations and have been mandated to attend by their faculty as part of sanctioning.

\section{The Workshops}

The workshops are delivered throughout the year, though we experience peak periods of demand that often coincide with mid-terms or the exam period at the end of each semester. Since their introduction in 2016, the number of attendees has increased which has resulted in an increase in the number of workshops offered. During peak periods up to six weekly workshops can be offered over the course of three weeks. After the peak period one workshop is delivered per week, alternating between the Plagiarism workshop and the Collaboration workshop.

The students self-register for the workshops by using the university's online booking system. If they have been mandated to attend, they are issued a deadline for completion by their Associate Dean. The duration of each workshop is $90 \mathrm{~min}$ with a maximum capacity for in-person delivery of 28 students. Each workshop is delivered by one facilitator.

Conversations surrounding the theme of academic misconduct can be highly emotive and negatively charged, even for those students who are not responsible for an academic misconduct violation but are answering to an accusation of one (Latopolski and Bertram Gallant, 2020). A students' emotional state can be adversely affected by the stress caused by the academic misconduct investigative process itself (Baird \& Dooey, 2014). In our practice, we observe the outward expression of a students' prior experiences with the process. Students overtly display a range of emotions; distress, anxiety, vulnerability, sensitivity or embarrassment, anger and frustration. In the workshops, these emotions present in several ways in student behaviours. For example, some students will position themselves furthest away from the facilitator and other students, they may display defensive body language, avoiding eye contact with facilitator or with other students and appear closed to conversation. 
We are intentional about framing each workshop as a learning opportunity for all students regardless of what their previous relationship with the academic integrity process may be, however based on institutional data and workshop participation, we can discern that approximately $95 \%$ of student attendees are mandated to attend. Although the decision to maintain an open workshop model poses challenges in that we are unable to determine the few students who are attending the session out of their own volition, this model provides us with an opportunity to protect student privacy, which we determined was of primary concern in establishing a safe learning environment for our mandated students. To further reinforce that anonymity, we do not ask for introductions in the room, taking attendance through student ID numbers. The relief in the room can be palpable. Students markedly change their body language, reacting in a way that suggests that they were anticipating a negative experience or were preparing for a combative session.

\section{Students Reported for Academic Misconduct}

Similar to our experience above, studies of students reported for academic integrity violations, though limited, demonstrate that these students experience a range of negative emotions as a direct result of their experience with the academic misconduct process (Pitt et al., 2020; Sutherland Smith, 2013). For instance, Pitt et al. report some students that have experienced academic misconduct allegations describe the experience as "the hardest, most challenging or worst experience of their lives" (2020, p. 5). That same study contains numerous impactful quotations from students who described the emotional impact of the accusation. Students comment that the experience "...was the worst phase of my life maybe" (2020, p. 5) and "If I could just describe that period, there's nothing darker than that, that I have experienced in my whole life. It was just a mixture of stress, embarrassment, mixture of losing my future, losing what I have been working for and towards. Honestly it was really bad" (Pitt et al., 2020, p. 5). Likewise, in Sutherland Smith's (2013) study engaging students who have been reported for academic integrity breaches related to collusion, shared that they "felt like a criminal" (p. 57). These previous negative interactions and the associated emotions illustrates why educating these students is unlike educating students who have yet to have a violation. As practitioners we may categorize the workshops as educational, realizing the intrinsic benefit of this developmental process, yet we must anticipate and acknowledge that to these students the workshop is not initially perceived as educational, it is simply an extension of the sanctions issued by faculty. In fact, mandatory attendance at academic integrity workshops is listed under 'educational sanctions' in our institutional policy. We acknowledge the place for formal academic integrity processes and the practice of sanctions. However, as we will discuss below, sanctioning practices framed within potentially alienating ethical-legal academic integrity discourses pose significant challenges in creating positive educational experiences for students who have had experiences with academic misconduct. A review of the broader academic integrity literature as well as 
the ethical decision-making scholarship related to academic integrity, demonstrates an increasing trend towards more nuanced understandings of how students encounter academic integrity. This literature described below, has been important in guiding our workshop development in response to the particular challenges of our teaching context. In the section below, we provide an overview of this scholarship.

\section{Reframing Ethical-Legal Academic Integrity Discourses}

In moving toward educational approaches for supporting students with reported instances of academic misconduct, we have sought to develop teaching and learning practices that reframe traditional ethical and legal academic integrity discourses and focus on developmental approaches. Much work has been done in problematizing the predominant academic integrity institutional frames of morality and rule compliance. In challenging these perspectives, Bertram Gallant (2008) emphasizes the binary nature of these perspectives and the failure to take into consideration broader "organizational, institutional [and] societal" (p. 49) contexts that impact of academic integrity issues. For instance, we have found in our discussions with students that there are significant disciplinary differences in relation to notions of groupwork and what constitutes a breach in academic integrity. Research on unauthorized collaboration confirms students lack clarity in distinguishing collusion violations from legitimate group learning (Sutherland-Smith, 2013). Our experience in our workshops confirms that students are often unable to identify differences between collusion and collaboration.

In addition, the "hazy nature of plagiarism" (Ashworth et al., 1997, p. 191) in particular, has been emphasized in several studies engaging students in discussions of academic integrity (Adam et al., 2017; Ashworth et al., 1997; Gullifer \& Tyson, 2010). Price's (2002) analysis of integrity policies illustrates the complex and contextualized nature of plagiarism that defies institutions' attempts to present the construct as "fixed and absolute" (p. 89). This lack of clarity points to significant problems with the positioning of academic integrity as an immoral act or unwillingness to follow rules and raises issues of intention. However, in spite of recommendations to do so (Bertram Gallant, 2008), scholars point out that there is often little to no distinction given in academic integrity policies between intentional and unintentional plagiarism (Price, 2002).

Given the complexities of the skills needed in incorporating the voices of others in academic work and the nuanced understandings required in distinguishing when and how it is acceptable to work with others, framing academic integrity as part of students' overall development as learners seems much more appropriate. We would argue that this is particularly important in approaches to supporting students who have violated the academic integrity policies. As discussed above, our experience with engaging this student population is that those students who are on the receiving end of academic integrity processes framed as immoral or dishonest acts can come to us feeling alienated, vulnerable and somewhat let down by their institution. This 
is confirmed by Sutherland-Smith's (2013) study of students who went through the academic integrity process for collusion, with students expressing feelings of low academic self-worth, anger and continued confusion following their conduct experience.

This is not to ignore that there are academic integrity issues that do activate ethical questions, however. Although, we adopt a teaching and learning approach in our workshops rather than an overall ethical-legal framework, we follow East's (2010) view that there are times when students engage in behaviours that they themselves recognize as lapses in personal ethics and that as an academic community are more straightforwardly identified as unethical. As East points out, cheating may be one of those particular instances. In my own experience (Roxanne) as a former academic writing instructor, my assumptions that academic integrity was primarily an issue of convention were significantly challenged in the first meeting I encountered with a student who submitted a purchased paper. Important to academic integrity education for students who have been reported for academic misconduct issues in our view then, is the necessity of holding space for academic integrity as potentially an issue of "morality or convention" (East, 2010, p. 74). Our approach to supporting the learning of students who have been reported for academic misconduct, is therefore responsive to both possible origins of students' actions; that is, challenges in understanding institutional conventions, challenges with decision-making in alignment with the values of the institution or a blend of both. We now turn to the significant body of literature on the application of ethical decision-making frameworks that has emerged in response to the ethical implications of students' academic integrity decisions.

\section{Ethical Decision-Making}

Similar to conversations more broadly on academic integrity, ethical decision-making scholarship has also become increasingly more sophisticated in its depiction of students' academic integrity decision-making practices. Early literature tended to frame academic misconduct situations as an example of a moral situation or an ethical dilemma; where the student was expected to discern the correct from the incorrect decision. If the student were to make an incorrect decision, Dalton (2015) terms this an "ethical failure" (p. 72), a "moral situation[s] in which students act in unethical ways." (p. 74). For several decades scholars have attempted to explain how individuals respond to ethical dilemmas in a field of study known as ethical decision-making. Much of this early research utilized seminal work by Kohlberg and his theory of moral development which dominated the literature from the 1960s. Building on the early work of Piaget, Kohlberg was focused on the moral development of individuals, describing how they move unidirectionally through three levels of moral reasoning and six sub-stages. This was suggested as being predictive of an individual's ability to reason in a given situation (Kohlberg, 1984). Much emphasis is placed on a student's level of moral reasoning in relation to ethical decision-making with several studies concluding that students with a high level of moral reasoning 
are less likely to make poor ethical choices (Cummings et al., 2001; Malinowski \& Smith, 1985). Despite critique of Kohlberg's research, the hierarchical nature of this research formed the basis for subsequent ethical decision-making theories, models and tests and its application across many situations and contexts, such as Ethics of Care (Gilligan, 1993), the Defining Issue Test (Rest, 1986), the Person-Situation Interactionist model (Trevino, 1986), the Issue-Contingency Model (Jones, 1991), the Action-Controlled model (Ferrell et al., 2016), the Moral Balance Model (Nisan, 1991), and the Moral Judgment Test (Lind, 2008). More recently, contemporary models highlight the influence of both individual and situational factors on the ethical decision-making process. In combining these two areas Schwartz (2016) proposed an Integrated Ethical Decision Making model that recognizes the complexity of the individual, noting that ethical behaviour is contingent on which individual is facing the dilemma. This offers reasoning as to why individuals do not respond identically and according to predetermined outcomes.

Despite the theoretical concepts, models and tests that outline what we expect the rationale behind ethical decision-making to be, students still make decisions that contradict theoretical expectations. The ethical decision-making process is multifaceted; a complex consolidation of factors pertaining to the individual, the situational context and any issue-specific variables. No one theory is able to fully explain the intricacies and combinations of variables that converge in that moment of decision-making and influence a student's choice, however two themes associated with decision-making in misconduct breaches can be identified: a lack of awareness or error in understanding institutional rules leading to a question of intentionality, and the multicultural and diverse nature of the student population within post-secondary education.

One crucial element of the decision-making process requires the individual to identify that they are facing an ethical dilemma. This would be the basis of a discussion on intentionality; an individual making a conscious decision to violate a rule. Barnhardt (2016) argues that in some academic misconduct cases the student has been unable to distinguish intentionality and that interpreting the students' incorrect behavioral choice as a lack of morality is problematic. Certainly, it is noted by Christensen Hughes and McCabe (2006a) that "many students may engage in these behaviours simply because they don't believe they are wrong" (p. 18). Therefore, a student should not be deemed morally deficient when a decision breaches the academic misconduct policy if there was a lack of awareness that the situation presented is an ethical dilemma. Once the student has identified the situation as relating to academic integrity, the focus can then shift from a question of intentionality to one of decision-making.

In recognizing that even those individuals who demonstrate a high level of morality do still commit acts that are considered academically dishonest (Heriyati \& Ekasari, 2020), we are drawn to consider the conflict that presents when prior experiences and personal values encounter institutional rules. Such differences are often the starkest between westernized and non-westernized cultures. For example, in China, students engage in copying behaviour, not to cheat, but to obtain their grade in the most efficient manner (Robinson \& Kuin, 1999) and in Russia, not only is plagiarism 
considered normal practice, but students progressing into higher education are noted to be more vulnerable to collusion-based activities due to their extensive exposure to group work in early schooling (Frost \& Hamlin, 2015). Christensen Hughes and McCabe (2006b) in their investigation of Canadian students also identify national culture as a contributing influence in students' academic integrity behaviours. These examples remind us that students are making decisions that are grounded in prior, culturally-influenced experiences. In addition to the complexities brought by prior experience and culture, the process of decision-making can also be influenced by their personal values (Weber, 2019). Academic misconduct may present as an ethical issue, but it is also combined with values that themselves are inextricably shaped by culture (Zhang \& Yin, 2020). Students from different cultures and countries also have differing personal values and these personal values can be predictors of a student's decision-making (Arambewela \& Hall, 2011). The increasingly nuanced perspectives that emerge from within both ethical decision-making literature and literature on academic integrity discourses, in addition to our own day to day engagement with students who share their encounters with academic integrity have led us to shape our practice in various ways. These practices, described below, include using a standards of practice frame in initiating academic integrity conversations (Bertram Gallant, 2008) and engaging students in applied decision-making practice through pedagogy centering on nuanced discussions and authentic scenarios.

\section{A Standards of Practice Frame}

In the recommendations section of Academic Integrity in the twenty-first century, Bertram Gallant advocates for adopting a standards of practice frame to "guide faculty and student behaviors for the enhancement of the teaching and learning environment" (2008, p. 98) similar to codes of conduct found in professional contexts. Although standards of practice models necessarily involve ethical considerations, they are tangible examples of contextualized ethical values, values that have been operationalized within a specific community. With this distinction from the traditional positioning of academic integrity as an expression of 'universal' values (East, 2010), introducing academic integrity to students as values that are shaped and enacted within the context of the institution, places a much greater emphasis on the newcomer's role as a learner. In her discussion of plagiarism, Price (2002) argues for the value of being transparent with students about its contextualized and shifting nature. She writes:

\footnotetext{
We can explain that what we call plagiarism is located in a specific setting: this historical time, this academic community. We can demonstrate that ideas such as "common knowledge" and "original" are informed by their particular contexts. And once we have acknowledged to students and ourselves that plagiarism is part of an ongoing, evolving academic conversation, we can invite students to add their own voices to that conversation. (p. 90)
}

In the development of our workshops, we have found the standards of practice framing of academic integrity particularly helpful in engaging students who have 
been reported for academic misconduct in positive teaching and learning dialogues for several reasons which we elaborate on below. As an example of this in practice, one activity we begin a session with involves asking students to generate words that come to mind when they think of the word integrity, first on their own and then with a partner. After a short time of partner discussion, we ask each pair to share one word with the group and record each contribution, so they are visible to everyone. We then discuss the similarities in the words that were generated as a group, words such as honesty, respect, responsibility, etc. and compare those to definitions of academic integrity as well as professional codes of conduct found in Engineering and other disciplines. In addition to beginning the session interactively and in such a way that we hope validates students' prior knowledge, acknowledging the similarities in values that emerge within our classroom community and the definitions across different communities demonstrates the important 'integrity' learning that is required in order to understand the nuances of how integrity is operationalized within whatever communities we engage.

A standards of practice framing acknowledges integrity and thus, academic integrity as an ongoing learning process that students engage with as members of the community. It acknowledges that certain conventions that may seem arbitrary (East, 2010) initiate from particular values in the community and that as we encounter these conventions for the first time it is understandable to question their relevance and need support in their application. Setting up academic integrity as an ongoing learning process illustrates for students that asking questions about academic integrity is necessary to engaging in a community with integrity. This moves academic integrity understandings beyond rules to be memorized, to a recognition that students need to actively apply the general principles of academic integrity to ever new situations. This is important in particular for students who have had violations and may be extremely anxious about having another issue. When we position academic integrity from an ethical-legal perspective as simple rules within a policy and students who fail to apply these rules as lacking in morality, we effectively shut down a dialogue and inhibit students from asking good questions about how academic integrity principles apply in their day-to-day experience. This is significantly problematic for the future success of students who have experienced violations and for whom a second violation could potentially end their academic study.

In reviewing literature related to educational approaches involving the conventions of academic integrity, scholarship on teaching students to avoid plagiarism in the context of academic writing has been most prominent. This work has emphasized the need to move beyond sharing policy documents to instead focus on supporting students' understanding and development of skills associated with successful academic writing that incorporates the voices of others (Price, 2002). There is consensus in the literature that avoiding plagiarism, as embedded in the process of learning to write in academic contexts, involves a number of complex skills ranging from critical reading to shaping academic voices in support of an argument (Adam et al., 2017; Powell \& Singh, 2016; Vardi, 2012). Powell \& Singh (2016) distinguish between "conceptualisation" (p. 16) and "application" (p. 16) in relation to students' understanding of plagiarism, with conceptualisation involving 
naming and identification of plagiarism and application the ability to apply this understanding to new learning environments. Their study in which students experienced scaffolded instruction and practice, illustrated that educational interventions can support students' abilities in both conceptualizing and applying an understanding of plagiarism. Schuetze (2004) found a similar benefit in students' understanding in an evaluation of teaching strategies that allowed students to practice skills associated with the academic writing conventions of paraphrasing and citation.

Scholarship on plagiarism has also been the origin of most critical work on academic integrity, with scholars questioning "the assumptive stances taken by the institution" (Bertram Gallant, 2008, p. 57) and advocating for an emphasis on the contextualized nature of definitions of plagiarism as they are applied in Western institutions (Price, 2002). These critical perspectives have influenced academic integrity pedagogies that focus on presenting definitions of plagiarism as shifting and unstable and as such, necessitate students' involvement in a process of ongoing learning (Price, 2002). Situating notions of plagiarism as contextualized conventions, rather than traditional ethical discourses, provides an opportunity to openly discuss rationalizations and values that underpin current practices within Western academia (East, 2010), acknowledge that different historical and cultural practices exist (Howard, 1995 ) and invite students to engage actively in understanding and querying conventions as participants within a discourse community (Price, 2002). Overall, the practice of engaging students in discussion about conventions as important to supporting students' learning of academic integrity is emphasized in much of the literature on plagiarism (Price, 2002; Schuetze, 2004; Thomas \& Sassi, 2017) and appears also in recommendations for supporting students' understanding of collusion (Sutton \& Taylor, 2011).

\section{Addressing Ethical Decision-Making: Scenarios}

As discussed above, institutions may anticipate that ethical themes are universally understood and therefore, when presented with an ethical dilemma that contravenes institutional rules, an incorrect decision denotes a student that intended to breach the rule or one who has low morality. We challenge this notion of a decision being binary, rejecting the idea that decisions that result in a breach of the academic misconduct policy are wholly explained by a students' lack of morality or ethics, and should simply be punished. We have seen that the factors associated in making a decision in academic misconduct situations are multifaceted and complex. The diversity of students within individual post-secondary institutions results in a population that has extensively different personal values and ethical experiences that cannot simply be explained as a lack of morality. We must recognize that a student's prior ethical experience and personal values, which has the potential to be linked to a cultural component, has a role to play in ethical decision-making. Rather than a personal attack on their morality, students need support in understanding how the specific values of academic integrity are operationalized within the institution. 
While issues of unintentionality, through misidentification of the situation presenting as an ethical dilemma, may be rectified through exposure to, and discussion of, the relevant academic integrity policies, the roles that culture and value conflicts play in decision-making necessitates a different approach. Scenarios are utilized widely in the literature to aid in the development of student ethical decisionmaking, and in particular, can be used to explore those situations that have the potential to lead to academic misconduct violations. These scenarios are not simply a case study designed to identify right or wrong actions, they are more a complex narrative identifying multiple factors that we recognize can influence decision-making. Embedding ethical dilemmas into morally themed scenarios, to highlight the grey areas in such situations, enables a deeper discussion to take place that can facilitate thinking and reasoning (Wong, 2020) and in turn, allow students to successfully understand and navigate the situation. The method by which the scenarios are explored with students is important. The learning outcome of the scenarios should not simply be identifying the ethical dilemma, but also to identify skills that can be used to implement their ethical choice, allowing the students to simulate, rehearse and practice their actual responses and master the skills necessary to navigate the potential academic misconduct situations (Basak \& Cerit, 2019; Drumwright et al., 2015; Riemenschneider et al., 2016). In addition, we also propose that cultural themes and perspectives, prior experiences and personal values should form a major component of the decision-making conversation.

While the discussion of scenarios is frequented in the literature, the scenarios that are described above are used with students who have not yet had a misconduct violation. It is more difficult to identify scholarly pieces that focus specifically on our target population. Orr (2018) describes an academic integrity seminar that, similarly to ours, was not restricted to those that had an academic misconduct violation. Unfortunately, the seminar itself and the scenario-based activities were not described in detail. However, although we are unable to glean the specific activities that were used in the workshop, the student feedback obtained after the seminars shared by Orr allows us to conclude that those who have had a misconduct violation responded positively to this type of developmental education. This is also our experience in observing students' participation in scenario-based activities within our workshops. Below we present our practical approach to using scenario-based instruction to improve the ethical decision-making skills of students who have been mandated to attend academic integrity programing.

We use scenarios for the specific purpose of allowing students to practice their decision-making processes and skills to explore, propose and critique decisions without reprimand or judgement. The combination of factors that led to a violation are limitless and addressing each specific combination is impossible. In the workshops we encounter students that are keen to explore their own experiences of academic misconduct, but in that group programming setting accommodating the unique contextual situation of each student's academic misconduct violation is not possible. In an attempt to overcome this, we aim to combine an understanding of the academic integrity values and how they are operationalized in the institution, with specific delivery of related educational information and examples pertaining to the 
misconduct type of concern and then offer a range of scenarios to allow students to practice their decision-making skills. Similarly to Wong's (2020) description of moral stories, the scenarios produced for the academic integrity workshops are comprised of multiple characters (students, peers, friends, the university) which facilitate discussions of personal and societal perspectives on academic integrity situations. Intertwined with the characters are high stakes implications for not breaching the policy, e.g. failing a course, losing a scholarship, a friend not helped. Each scenario is framed by three main questions. Students are asked to comment on the behaviours within the case study that have the potential to lead to an academic misconduct, whether rationalizations are justified and what strategies could be adopted to avoid the situation. Students initially answer as anticipated, often very briefly, noting the obvious behaviours that put the student in the scenario at risk of an academic misconduct violation. Students can easily identify the rationalizations and very rarely accept them as valid justifications for the misconduct related behaviour. They are also able to offer basic strategies for avoiding the situation in the future.

This level of engagement and answering are witnessed more frequently in discussions around plagiarism, where the student can recite why citations and the requirement to paraphrase are important and how using reference management software, improving academic writing skills and addressing time management issues are potential strategies. However, scenarios concerning group work and helping a friend in need with an assignment are more complex to unpack with students. This is reflective of research in this area. Barrett \& Cox (2005) found that students were able to identify plagiarism as unacceptable practice but struggled more so with the distinction between collaboration and collusion. The variations in uncertainty about what is acceptable collaboration when two students work together was noted as being especially problematic with the influence of disciplines of study, where the distinction and acceptance is nuanced. In framing the situation as "the 'mythical line' between collusion and collaboration" (p. 55), Sutherland Smith (2013) presents the difficulties faced by students in attempting to understand what constitutes collaboration and collusion. Students highlighted discipline differences: "I don't think collusion is seen the same way by all areas of the university. [...] How consistent is this across the university anyway?" (p.54), their personal values in helping friends; "[...] some of the younger Vietnamese students were struggling with all the readings [...] As an older student $[\ldots]$ it is my moral obligation to help. I mean, what kind of person would I be if I did not help?" (p.56) as well as continued confusion after a breach of the policy; "When I got the letter, I felt like a criminal. The worst thing was I didn't know what I'd done wrong. I still don't!" (p. 57). In these conversations the role of the facilitator is paramount.

The facilitator for the workshops does not accept superficial answers to complex scenarios. They probe the student into deeper, more critical thinking. This questioning aims to encourage the student to be completely open and honest when answering, encouraging the student to apply their personal values, ethical experience and cultural perspectives against the situation. Questioning strategies include: could you honestly say no to a friend in need? What would that look like, what wording would you use? What if the stakes were high not breaching the rules resulted in you/ your 
friend failing a course/ reducing your Grade Point Average (GPA)/ risked losing a scholarship? In this type of questioning, we notice immediate discomfort from students and consider this a visual manifestation of their colliding personal values and prior ethical experience and culture with the institutional rules. Students are less fluid with their answers. The difficulty they have with articulating the practical aspect of the scenarios reflects what we know from the literature; students need to practice the skills necessary, and that includes what wording to use. This practice can take the form of role play. The facilitator plays the role of the student in need. In mimicking the scenario, the facilitator asks a student in the group for help. The student is encouraged to formulate and give a response to the facilitator.

At the end of each workshop, students are asked to reflect upon the session. To guide their reflection they are asked to anonymously answer two brief questions: what was one thing that surprised you and what will you take away from the session. Students most often comment on a specific misconduct type that they were not aware of (such as self-plagiarism), an impactful news story (e.g. the Measles, Mumps and Rubella vaccination fabrication) and the breadth of resources that are available to them to help support their studies. We have used this feedback to make amendments to the content of the workshops and also to produce additional online resources.

\section{Recommendations for Teaching and Learning}

As Bertram Gallant points out, regardless of proactive teaching and learning approaches to academic integrity, which we also participate in, there will likely always be students who engage in academic misconduct (2017), the reasons for which stem from lapses in decision-making, lack of awareness of institutional policies, or incongruent values to name a few. Moving away from moral or legal binaries in academic integrity instruction to instead focus programming on a scenario-based curriculum alongside a standards of practice framework can provide student affairs practitioners with a flexible and responsive approach to the difficult task of responding to student audiences with have a variety of experiences with academic misconduct that we often find ourselves in.

In our situation the nature and specific details of the students' academic misconduct violation is unknown. This can present a problem with content design for the workshop. Students can become frustrated if their academic misconduct case was a violation of exam regulations and cheating and yet they are mandated to attend workshops on plagiarism or collusion. Therefore, we develop scenarios that incorporate a variety of potential academic misconduct themes. We also maintain an open dialogue with faculty so that common trends or themes in academic misconduct cases can be identified and utilized to continually update the scenarios.

Programming needs to be current and responsive in order to be effective. In developing academic integrity workshops or programming, consider workshops that focus on other academic misconduct types such as cheating. There is perhaps a tendency to focus on what are considered to be the most common types of academic misconduct, 
such as plagiarism and collusion, in offering programming, but as we are experiencing with the COVID-19 pandemic there is a shift in the types and nature of cases. In our practice, where additional workshops have not been created, we include content in both workshops that cover all misconduct types, current trends and themes and facilitate discussion in those areas.

Student timetables are often very busy and inflexible which can leave little time to attend a workshop. Students should not be forced to miss a normal lecture due to the need to attend a workshop. In planning the timetable for the workshops, we aim to offer a variety of different days and times, sometimes offering early morning or later evening slots. Where students have a full course load and have a short timeframe with which to attend a workshop, we may meet with the student on a one-to-one basis. It is worthwhile for student affairs providers to collaborate with Associate Deans to stay informed of cases so that additional workshops can be added to the schedule.

\section{References}

Adam, L., Anderson, V., \& Spronken-Smith, R. (2017). It's not fair: Policy discourses and students' understandings of plagiarism in a New Zealand university. Higher Education, 74(1), 17-32. https://doi.org/10.1007/s10734-016-0025-9

Arambewela, R., \& Hall, J. (2011). The role of personal values in enhancing student experience and satisfaction among International postgraduate students: An exploratory study. Procedia-Social and Behavioral Sciences, 29, 1807-1815. https://doi.org/10.1016/j.sbspro.2011.11.428

Ashworth, P., Bannister, P., \& Thorne, P. (1997). Guilty in whose eyes? University students' perceptions of cheating and plagiarism in academic work and assessment. Studies in Higher Education, 22(2), 187-203. https://doi.org/10.1080/03075079712331381034

Baird, C., \& Dooey, P. (2014). Ensuring effective student support in higher education alleged plagiarism cases. Innovative Higher Education, 39(5), 387-400. https://doi.org/10.1007/s10755014-9285-4

Barnhardt, B. (2016). The epidemic of cheating depends on its definition: A critique of inferring the moral quality of cheating in any form. Ethics \& Behavior, 26(4), 330-343. https://doi.org/10. 1080/10508422.2015.1026595

Barrett, R., \& Cox, A. L. (2005). At least they're learning something: The hazy line between collaboration and collusion. Assessment and Evaluation in Higher Education, 30(2), 107-122. https://doi.org/10.1080/0260293042000264226

Basak, T., \& Cerit, B. (2019). Comparing two teaching methods on Nursing students ethical decisionmaking level. Clinical Simulation in Nursing, 29, 15-23. https://doi.org/10.1016/j.ecns.2019. 02.003

Bertram Gallant, T. B. (2008). Academic integrity in the twenty-first century: A teaching and learning imperative. ASHE Higher Education Report, 33, 5. https://doi.org/10.1002/aehe.3305

Christensen Hughes, J. M., \& McCabe, D. L. (2006a). Academic misconduct within higher education in Canada. Canadian Journal of Higher Education, 36(2), 1-21. https://doi.org/10.47678/cjhe. v36i1.183525.

Christensen Hughes, J. M., \& McCabe, D. L. (2006b). Understanding academic misconduct. Canadian Journal of Higher Education, 36(1), 49-63. https://journals.sfu.ca/cjhe/index.php/cjhe/art icle/view/183525

Cummings, R., Dyas, L., Maddux, C. D., \& Kochman, A. (2001). Principled moral reasoning and behavior of preservice teacher Education students. American Educational Research Journal, 38(1), 143-158. https://doi.org/10.3102/00028312038001143 
Dalton, J. C. (2015). Making moral mistakes: What ethical failure can teach students about life and leadership: Making moral mistakes. New Directions for Student Leadership, 2015(146), 71-79. https://doi.org/10.1002/yd.20136

Drumwright, M., Prentice, R., \& Biasucci, C. (2015). Behavioral ethics and teaching ethical decision making. Decision Sciences Journal of Innovative Education, 13(33), 431-458. https://doi.org/10. 1111/dsji.12071

East, J. (2010). Judging plagiarism: A problem of morality and convention. Higher Education, 59(1), 69-83. https://doi.org/10.1007/s10734-009-9234-9

East, J., \& Donnelly, L. (2012). Taking responsibility for academic integrity: A collaborative teaching and learning design. Journal of University Teaching and Learning Practice, 9(3), 1-11. https://ro.uow.edu.au/jutlp/vol9/iss3/2

Ferrell, O. C., Gresham, L. G., \& Fraedrich, J. (2016). A synthesis of ethical decision models formarketing. Journal of Macromarketing, 9(2), 55-64. https://doi.org/10.1177/027614678900 900207

Frost, J., \& Hamlin, A. (2015). A comparison of international student attitudes concerning academic dishonesty. Journal of International Business Research, 14(2), 153-165. https://www.abacad emies.org/articles/jibr_vol_14_no_2_2015.pdf

Gilligan, C. (1993). In a different voice: Psychological theory and woman's development. United States: Harvard University Press.

Gullifer, J., \& Tyson, G. A. (2010). Exploring university students' perceptions of plagiarism: A focus group study. Studies in Higher Education, 35(4), 463-481. https://doi.org/10.1080/030750 70903096508

Heriyati, D., \& Ekasari, W. F. (2020). A study on academic dishonesty and moral reasoning. International Journal of Education (12)2, 63-72. https://doi.org/10.17509/ije.v12i2.18653

Howard, R. M. (1995). Plagiarisms, authorships, and the academic death penalty. National Council of Teachers of English, 57(7), 788-806. https://www.jstor.org/stable/378403.

Jones, T. M. (1991). Ethical decision making by individuals in organizations: An issue-contingent model. The Academy of Management Review, 16(2), 366-395. https://doi.org/10.2307/258867

Kohlberg, L. (1984). The psychology of moral development. Unites States: Harper \& Row.

Latopolski, K.E. and Bertrum Gallant, T.L. (2020). Academic Integrity. In D. M. Waryold, \& J. M. Lancaster (Eds.), Student conduct practice: The complete guide for student affairs professionals (2nd Edition). Stylus

Lind, G. (2008). The meaning and measurement of moral judgement competence. A dual-aspect model. In D. Fasko, Jr. \& W. Willis, W. (Eds.), Contemporary philosophical and psychological perspectives on moral development education. Hampton Press.

Malinowski, C. I., \& Smith, C. P. (1985). Moral reasoning and moral conduct: An investigation prompted by Kohlberg's theory. Journal of Personality and Social Psychology, 49(4), 1016-1027. https://doi.org/10.1037/0022-3514.49.4.1016

Nisan, M. (1991). The moral balance model: Theory and research extending our understanding of moral choice and deviation. In W. M. Kurtines \& J. L. Gewirtz (Eds.), Handbook of moral behavior and development. L. Erlbaum.

Orr, J. (2018). Developing a campus academic integrity education seminar. Journal of AcademicEthics, 16(3), 195-209. https://doi.org/10.1007/s10805-018-9304-7

Pitt, P., Dullaghan, K., \& Sutherland Smith, W. (2020). Mess, stress and trauma: Students experiences of formal contract cheating processes. Assessment and Evaluation in Higher Education, 1-14.https://doi.org/10.1080/02602938.2020.1787332

Powell, L., \& Singh, N. (2016). An integrated academic literacy approach to improving students' understanding of plagiarism in an accounting course. Accounting Education, 25(1), 14-34. https:// doi.org/10.1080/09639284.2015.1133311

Price, M. (2002). Beyond gotcha!: Situating plagiarism in policy and pedagogy. National Council of Teachers of English, 54(1), 88-115. http://www.jstor.org/stable/1512103

Rest, J. R. (1986). Moral development: Advances in research and theory. Praeger. 
Riemenschneider, C. K., Manly, T. S., \& Leonard, L. N. K. (2016). Using "giving voice to values" to improve student academic integrity in information technology contexts. Journal of Information Systems Education, 27(3), 183.

Robinson, V. M. J., \& Kuin, L. M. E. I. (1999). The explanation of practice: Why Chinese students copy assignments. International Journal of Qualitative Studies in Education, 12(2), 193-210. https://doi.org/10.1080/095183999236259

Schuetze, P. (2004). Evaluation of a brief homework assignment designed to reduce citation problems. Teaching of Psychology, 31(4), 257-259. https://doi.org/10.1207/s15328023top3104_6

Schwartz, M. S. (2016). Ethical decision-making theory: An integrated approach. Journal of Business Ethics, 139(4), 755-776. https://doi.org/10.1007/s10551-015-2886-8

Sutherland-Smith, W. (2013). Crossing the line: Collusion or collaboration in university group work? The Australian Universities Review, 55(1), 51-58. https://files.eric.ed.gov/fulltext/EJ1 004398.pdf

Sutton, A., \& Taylor, D. (2011). Confusion about collusion: Working together and academic integrity. Assessment and Evaluation in Higher Education, 36(7), 831-841. https://doi.org/10. 1080/02602938.2010.488797

Thomas, E. E., \& Sassi, K. (2017). An ethical dilemma and academic integrity: It is every English teacher's dream. The English Journal, 100(6), 47-53. https://www.jstor.org/stable/23047881

Trevino, L. K. (1986). Ethical decision making in organizations: A person-situation interactionist model. The Academy of Management Review, 11(3), 601-661. https://doi.org/10.2307/258313

Vardi, I. (2012). Developing students' referencing skills: A matter of plagiarism, punishment and morality or of learning to write critically? Higher Education Research and Development, 31(6), 921-930. https://doi.org/10.1080/07294360.2012.673120

Weber, J. (2019). Understanding the millennials' integrated ethical decision-making process: Assessing the relationship between personal values and cognitive moral reasoning. Business \& Society, 58(8), 1671-1706. https://doi.org/10.1177/0007650317726985

Wong, M.-Y. (2020). Beyond asking should and why questions: Contextualised questioning techniques for moral discussions in moral education classes. Journal of Moral Education. https://doi. org/10.1080/03057240.2020.1713066

Zhang, Y., \& Yin, H. (2020). Collaborative cheating among Chinese college students: The effects of peer influence and Individualism-Collectivism orientations. Assessment \& Evaluation in Higher Education, 45(1), 54-69. https://doi.org/10.1080/02602938.2019.1608504

Lee-Ann Penaluna is the Coordinator, Academic Integrity Programs at the University of Calgary. In addition to developing institution-wide initiatives that increase students understanding of academic integrity, she also provides educational support to students who have had academic misconduct violations. In her previous role as the Head of Higher Education at Abingdon and Witney College (UK), Lee-Ann was the Academic Misconduct Officer, responsible for the case management of academic integrity violations. Lee-Ann holds an MSc from Aberystwyth University and is currently studying for a PhD in the Department of Educational Research at Lancaster University.

Roxanne Ross is currently the Director, Student Success Centre at the University of Calgary. Her role involves working collaboratively within the institution to support the development and delivery of learning, writing and advising services for undergraduate and graduate students. Roxanne's previous professional work includes the Coordinator of Writing Support Services at Carleton University as well as teaching within the field of post-secondary English for Academic Purposes (EAP). Roxanne holds a Masters of Applied Language Studies from Carleton University and is currently studying in the Educational Doctorate program at the University of Calgary. 
Open Access This chapter is licensed under the terms of the Creative Commons Attribution 4.0 International License (http://creativecommons.org/licenses/by/4.0/), which permits use, sharing, adaptation, distribution and reproduction in any medium or format, as long as you give appropriate credit to the original author(s) and the source, provide a link to the Creative Commons license and indicate if changes were made.

The images or other third party material in this chapter are included in the chapter's Creative Commons license, unless indicated otherwise in a credit line to the material. If material is not included in the chapter's Creative Commons license and your intended use is not permitted by statutory regulation or exceeds the permitted use, you will need to obtain permission directly from the copyright holder.

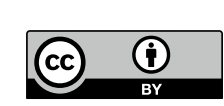

